\title{
Guillaume Tardif, Les Facecies de Poge. Traduction du 'Liber facetiarum' de Poggio Bracciolini
}

\section{Gianni Mombello}

\section{(2) OpenEdition}

10 Journals

\section{Édition électronique}

URL : http://journals.openedition.org/studifrancesi/34428

DOI : $10.4000 /$ studifrancesi.34428

ISSN : 2421-5856

Éditeur

Rosenberg \& Sellier

\section{Édition imprimée}

Date de publication : 1 novembre 2005

Pagination : 394-395

ISSN : 0039-2944

\section{Référence électronique}

Gianni Mombello, « Guillaume Tardif, Les Facecies de Poge. Traduction du 'Liber facetiarum' de Poggio Bracciolini », Studi Francesi [En ligne], 146 (XLIX | II) | 2005, mis en ligne le 30 novembre 2015, consulté le 19 avril 2021. URL : http://journals.openedition.org/studifrancesi/34428 ; DOI : https://doi.org/ 10.4000/studifrancesi.34428

Ce document a été généré automatiquement le 19 avril 2021.

\section{(c)}

Studi Francesi è distribuita con Licenza Creative Commons Attribuzione - Non commerciale - Non opere derivate 4.0 Internazionale. 


\title{
Guillaume Tardif, Les Facecies de Poge. Traduction du 'Liber facetiarum' de Poggio Bracciolini
}

\author{
Gianni Mombello
}

\section{RÉFÉRENCE}

GUillaume TARDIF, Les Facecies de Poge. Traduction du 'Liber facetiarum' de Poggio Bracciolini. Edition critique par FRÉDÉRIC DUVAL et SANDRINE HÉRICHÉ-PRADEAU, Genève, Droz, 2003 («Textes Littéraires Français», 555), pp. 314.

1 Après les trois éditions parisiennes du XVI ${ }^{e}$ siècle (Veuve de Jean Trepperel, entre 1517 et $1525=\mathrm{A}$; Jean Bonfons, $1549=\mathrm{D}$; Nicolas Bonfons, 1574) et les deux lyonnaises (Olivier Arnoullet, après 1514-15 = B; Idem, après 1514-1515 = C), cette traductionadaptation de cent quinze pièces sur les deux cent soizante-treize que compte le Liber facetiarum avait été presque complètement oubliée. C'est seulement en 1878 qu'Anatole de Montaiglon en donnait une nouvelle édition sur l'exemplaire $C$ (Paris, Bibliothèque de l'Arsenal: $8^{\circ}$ B 30471 Rés.) incomplet du prologue et de trois (p. 7, ou plutôt cinq, p. 61) facéties.

2 Lionello Sozzi, en 1967 et ensuite en 1977, en 1982 et encore en 2002 (Les Facéties du Pogge et leur diffusion en France dans Rome n'est plus Rome. La polémique anti-italienne et autres essais sur la Renaissance, suivis de 'La dignité de l'homme', Paris, H. Champion, 2002, «Etudes et Essais sur la Renaissance», LXI, pp. 167-80) et Peter Koij en 1969 ont attiré l'attention des chercheurs sur cette œuvre de Tardif. En voici maintenant une nouvelle édition munie d'une double introduction littéraire et philologique.

Le texte reproduit est celui de A, dont les leçons rejetées figurent en bas de page avec la mention du, ou des exemplaires qui ont fourni la correction (parmi lesquels un témoin $\mathrm{x}$ non identifié). Un choix de variantes, qui ont été jugées intéressantes du point de vue sémantique, est placé à la fin de la transcription de A (pp. 243-56). Suivent des notes 
linguistiques et historiques (pp. 257-79), un glossaire substantiel (pp. 281-302), une table des facéties traduites avec leur titre tiré de A (pp. 303-10) et un index thématique bref, mais très utile (pp. 311-14).

4 L'introduction littéraire (pp. 11-52) est due à Frédéric Duval. Elle nous apprend à lire cette traduction «sans garder un œil rivé sur le texte latin» (p. 52), en d'autres termes, à considérer de façon autonome le travail de réécriture auquel Guillaume Tardif s'est livré. En effet, certaines caractéristiques de la facétie de Poggio changent notablement sous la plume du traducteur, qui doit respecter certaines contraintes sociales et qui théâtralise le récit en passant du discours indirect au discours direct toutes les fois qu'il le peut. Il sait présenter adroitement l'histoire, il s'efforce d'être clair, non sans infliger au texte de départ quelques entorses. Sa moralisation de convention, absente de l'original latin, est collée au récit sans conviction.

5 Cela n'est pas dit en clair, mais, en lisant ces pages, on a l'impression que Fr. Duval tend non seulement à réévaluer cette œuvre de Guillaume Tardif - ce qui nous trouve parfaitement d'accord -, mais à la placer au-dessus du texte de Poggio, ce qui serait peut-être aller un peu trop loin.

6 La seconde partie de l'introduction (pp. 53-81) est tout aussi intéressante. Elle nous rappelle qu'il a existé une édition incunable de cette traduction (est-ce le témoin $\mathrm{x}$ postulé?), édition mentionnée par l'inventaire de la librairie de Charles d'Angoulême dressé à Cognac en 1496.

7 La description matérielle des éditions qui ont survécu, leur localisation, ainsi que l'analyse de leur contenu fait ressortir l'importance de A choisi comme texte de base et corrigé sur B; mais parfois les cinq témoins ne suffisent pas pour établir un texte correct, d'où la nécessité de nombreuses interventions.

8 Les pages qui suivent (65-81) décrivent la langue de A. Ayant travaillé sur les Ditz des sages hommes du même Tardif (c. 1492), ces remarques nous ont été très utiles, parce qu'elles confirment les hésitations graphiques et partant aussi phonétiques, morphologiques et syntaxiques des éditions anciennes contenant des œuvres françaises de cet humaniste et donc l'intérêt qu'il y a à les regarder de plus près.

9 Dans ce cas, un relevé de toutes les variantes des témoins conservés, qui s'échelonnent sur un demi siècle, aurait été le bienvenu, mais on ne peut pas demander trop aux deux éditeurs, qui ont déjà fourni un excellent travail. 